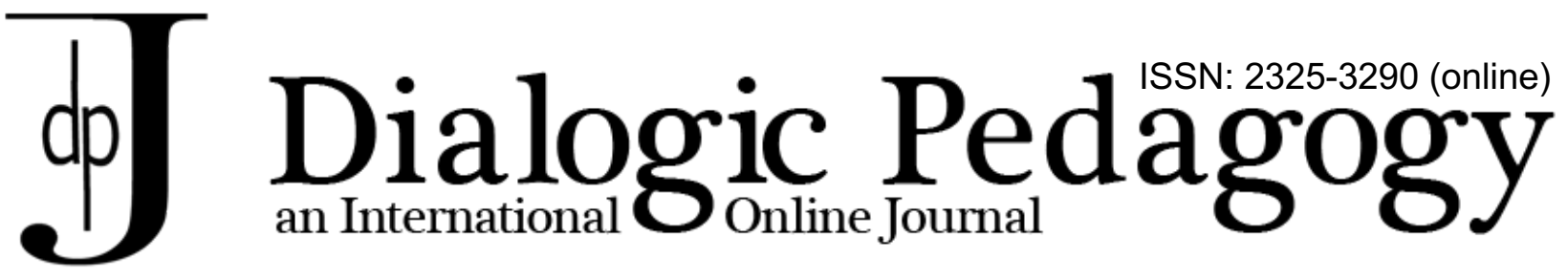

\title{
Controversies and consensus in research on dialogic teaching and learning
}

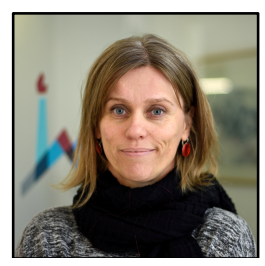

Christa S. C. Asterhan

The Hebrew University of Jerusalem

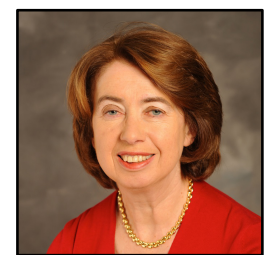

Christine Howe

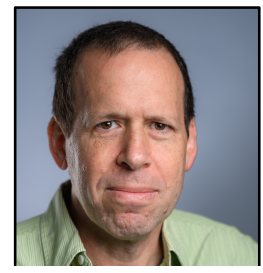

Adam Lefstein
Ben Gurion University of the Negev

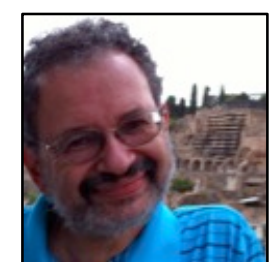

Cambridge University

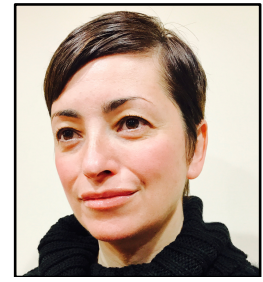

Alina Reznitskaya

Montclair University

\begin{abstract}
Scholarly interest in dialogic pedagogy and classroom dialogue is multi-disciplinary and draws on a variety of theoretical frameworks. On the positive side, this has produced a rich and varied body of research and evidence. However, in spite of a common interest in educational dialogue and learning through dialogue, cross-disciplinary engagement with each other's work is rare. Scholarly discussions and publications tend to be clustered in separate communities, each characterized by a particular type of research questions, aspects of dialogue they focus on, type of evidence they bring to bear, and ways in which standards for rigor are constructed. In the present contribution, we asked four leading scholars from different research traditions to react to four provocative statements that were deliberately designed to reveal areas of consensus and disagreement ${ }^{1}$. Topic-wise, the provocations related to theoretical foundations, methodological assumptions, the role of teachers, and issues of inclusion and social class, respectively. We hope that these contributions will stimulate cross- and trans-disciplinary discussions about dialogic pedagogy research and theory.
\end{abstract}

Christa Asterhan is an Assistant Professor at the Seymour (Shlomo) Fox School of Education of the Hebrew University in Jerusalem, where she also received her doctoral degree in Educational Psychology and heads the Learning \& Interaction Lab. In her research, she explores the cognitive and social aspects of human interaction and human communication and how these affect learning. She strongly believes in and promotes a multidisciplinary and multi-method approach to the study of learning through social

${ }^{1}$ The authors of this article are five scholars, the dialogic provocateur and the four respondents. The order of appearance of the authors was determined alphabetically. 
interaction. Topic-wise, she has conducted research on collaborative learning, classroom dialogue and argumentation, teacher facilitation of learning dialogues, computer-mediated learning interactions, social media and education, conceptual change, and teacher pedagogical reasoning. Together with Lauren Resnick and Sherice Clarke, she edited the 2015 AERA volume Socializing Intelligence through Academic Talk and Dialogue.

Christine Howe is Professor of Education (Emerita) at Cambridge University. Her research lies at the intersection of psychology, education, and linguistics, with major interests including children's communicative, linguistic and peer relational skills, children's reasoning in science and mathematics, and dialogue and learning during peer collaboration and teacher-led instruction. Christine has received moreor-less continuous funding from the ESRC (the UK's premier sponsor of social science research) for over 30 years, as well as securing awards from British Academy, Leverhulme, Nuffield, and various governmental and local authority sources. Her most recent ESRC-funded project addressed 'Classroom dialogue: Does it really make a difference for student learning?' Christine has published seven books and over 200 peer-reviewed articles and chapters, and she has acted as editor for three academic journals while also serving on many editorial boards. She has held strategic appointments at the local, national and international levels relating to research and research training.

Adam Lefstein is Associate Professor and Chair of the Department of Education at the Ben-Gurion University of the Negev in Israel, where he conducts research and teaches about pedagogy, classroom interaction, teacher learning and educational change. He is particularly interested in the intersection between research and professional practice, and how to conduct research that is meaningful, rigorous and helpful for educators. He co-directs (with Dana Vedder-Weiss) the Laboratory for the Study of Pedagogy, an interdisciplinary research group that investigates Israeli pedagogy, schooling, educational policy and change, and processes of knowledge sharing with practitioners, policy-makers and the public. His current and recent research includes a study of Israeli culture and primary pedagogy, an investigation of videobased dialogic debrief conversations, a design-based implementation study of teacher leadership and professional discourse, an experimental study of academically productive talk in primary language classrooms and an ethnographic investigation of language, class and classroom participation.

Eugene Matusov is a Professor of Education at the University of Delaware. He studied developmental psychology with Soviet researchers working in the Vygotskian paradigm and worked as a schoolteacher before immigrating to the United States. He uses sociocultural and Bakhtinian dialogic approaches to education. His recent books are: Matusov, E. (2017). Nikolai N. Konstantinov's authorial math pedagogy for people with wings, Matusov, E. \& Brobst, J. (2013). Radical experiment in dialogic pedagogy in higher education and its Centauric failure: Chronotopic analysis, and Matusov, E. (2009). Journey into dialogic pedagogy.

Alina Reznitskaya is a Professor at Montclair State University, USA. She received her doctoral degree in Educational Psychology from the University of Illinois and did her post-doctoral research at Yale University. Alina has acquired expertise in educational psychology, quantitative research methodology, and educational measurement, and she teaches undergraduate and graduate courses on these topics. Alina's research interests include investigating the role social interaction plays in the development of argument literacy, designing measures of argumentation, and examining professional development efforts that help teachers learn to facilitate argumentation during class discussions. Alina has been awarded research grants by the Spencer Foundation and the U.S. Department of Education, Institute of Education Sciences. Dr. Reznitskaya's work has appeared in a variety of journals and edited books, including Educational Psychologist, The Reading Teacher, Contemporary Educational Psychology, Cambridge Journal of 
Education, Elementary School Journal, Discourse Processes, Comprehension Instruction: ResearchBased Best Practices, and Positive Psychology in Practice.

\section{Introduction}

Scholarly interest in dialogic pedagogy and classroom dialogue cuts across disciplinary boundaries, such as psychology, pedagogy, ethnography, linguistics, cognitive science and philosophy. This multi-disciplinary focus on a common object of interest has produced a rich and varied body of theory and research. Yet, perhaps not surprisingly, it has also created confusion, frictions and even collisions, especially as scholars from different research traditions have begun to meet and discuss each other's work more frequently at international meetings and/or have tried their hand at integration for written reviews and collections. Whereas some apparent differences appear to be surface level only, others may be more profound and paradigmatic. For example, the meaning of commonly used labels, such as dialogue, talk, learning and pedagogy, vary across different fields. Even the reasons for studying classroom dialogue differ greatly - e.g., dialogue as a goal in and of itself, as an instrument to achieve something else, as a competency, as a methodology for studying other phenomena, or as a byproduct.

As scholars of dialogue, we believe it is imperative to practice what we preach and stimulate productive discussions across and within different research communities of dialogue pedagogy, to map both minor as well as major points of contention, and to identify areas of consensus. To this end, a multidisciplinary discussion panel was organized and hosted at the 2018 Biennial EARLI Conference on Argumentation, Dialogue and Reasoning (Jerusalem, Israel). Christa Asterhan formulated four provocations, each chosen to address a key issue (past, present or future) in research on dialogic education. Four leading scholars from different research disciplines, theoretical backgrounds and/or research communities were invited to react to these provocations: Alina Reznitskaya, Adam Lefstein, Christine Howe and Eugene Matusov. Each of these well-known scholars has studied and written extensively about the role of dialogue in learning and teaching, whilst focusing on distinctively different types of questions and goals, employing different methods of investigation and working within different disciplinary and/or theoretical frameworks.

The format was slightly different from the usual conference discussion panel: Each panelist received the provocations a week in advance in order to prepare ${ }^{2}$. The session itself included four cycles of the following:

- Christa presented a provocation;

- The audience received 2 min of partner talk to discuss the provocation with the person sitting next to them, before giving the floor to the panel members;

- Each panel member received $2.5 \mathrm{~min}(150 \mathrm{sec})$ to react and present his/her viewpoint on the issue, in round robin style.

We have transcribed the panel member contributions, with slight adaptations to increase readability in the written format ${ }^{3}$. We share them here, in the hope of stimulating further cross- and trans-disciplinary discussions about dialogic pedagogy research and theory.

\footnotetext{
${ }^{2}$ The four panelists each referred orally to ideas and research that have been published by themselves and others. We have added the references to these publications in the written version, and in a compiled reference list.

${ }^{3}$ Unfortunately, the partner talk and general audience discussions during the session could not be transcribed and published.
} 
Provocation nr 1. The terms dialogic pedagogy and/or dialogic learning are used quite often and sometimes quite loosely in our field. It seems that different scholars do not necessarily mean the same thing. What is your (working) definition of dialogic pedagogy and/or dialogic learning and what are the pivotal features that set it apart from other common or well-known approaches?

\section{Alina Reznitskaya:}

I agree that dialogic pedagogy today represents a set of rather general principles, which can be activated in many different ways and result in quite distinct classroom practices. Moreover, at least in some versions, dialogic pedagogy implies the use of multiple discourse types, depending on specific instructional goals for students.

Our work has a narrower focus, with the main instructional goal of supporting the development of argumentation, and as a result, deeper understanding of the subject matter. To identify the normative type of discourse for this goal, we drew on the work of Douglas Walton who described different conversational contexts for argumentation, including inquiry, persuasion, and negotiation, among others (Walton, 1998). We also followed Maughn Gregory who applied Walton's work to education and suggested that inquiry dialogue is a normative type of talk for promoting reasoned argumentation (Gregory, 2007). The goal of inquiry dialogue is to collaboratively search for the most reasonable answer to a contestable question. During inquiry dialogue, participants not only are expected to defend their own positions and critically examine those of others (as in persuasion), but they may also need to give up or qualify their viewpoints in the face of previously overlooked evidence or faulty reasoning. Inquiry dialogue is not about determining who is right, but about collaboratively deciding on what is right, or the most reasonable. So, inquiry dialogue entails a systematic movement towards the truth (even if truth remains an unreachable ideal), and it relies on epistemic commitments and evaluation standards that support such movement.

Adam Lefstein:

First, let me just share my immediate, visceral response to this question, which was, "Oh no, why did I agree to be on this panel?" I feel rather boxed in by definitions. Especially definitions with a two-and-a-half-minute time limit. If forced, my definition, which I'm not going to give you, would include something about interactional structures (the give and take of exchange, reciprocity in the distribution of turns at talk), something about argument and critique (ideas are expressed, criticized and justified), something about voices (participants express their own ideas, in their own language, and address one another's ideas), something about stance (critical yet open), and something about relationships (of care and trust and inclusion), shared power and ownership. I'd also point out that some of these different aspects of the definition are in practice often in tension with one another - for example, critique and care, or orderly exchange and shared power - and all are in tension with various aspects of contemporary schooling, so this definition offers a general lay of the land rather than a particular path that one can unproblematically follow.

What sets this approach apart? Perhaps that it's rather convoluted and not terribly memorable? I would say that what we've tried to do in our work - I'm speaking here in Julia Snell and Aliza Segal's name as well (Lefstein, 2010; Lefstein \& Snell, 2014) - what we've tried to do is to offer an approach that is grounded in existing classroom conditions. Rather than starting with an ideal image of what we believe dialogue should look like and then criticizing teachers and pupils for not living up to that lofty standard, we've tried to start with the actual practices that we've encountered in classrooms. That is, to first seek to 
understand the rules of the classroom game and the conditions constraining teaching practice, and then work out from them to the development of dialogic possibilities. Second, our approach is multidimensional, that is we include numerous aspects of classroom communication and interaction, including communicative forms, interpersonal relations, the exchange and development of ideas and voices, power, and aesthetics. Finally, we view dialogue as a problem rather than a solution. We argue that dialogic pedagogy is most helpful as a set of dilemmas to consider, concepts to think with, commitments to pursue and balance, and practices to add to our repertoires. It is less helpful as a narrow best practice solution to each and every classroom situation. And that final point partially explains why I'm reluctant to define it.

\section{Christine Howe:}

I don't have a working definition of dialogic teaching and learning, because I don't actually need one for the research l've been doing recently. I fully agree that there is a lot of variation in the field, but I also think there is a lot of overlap once you rise above the terminological quagmire that besets this whole area. And what l've been doing in my most recent study (Howe, Hennessy, Mercer, Vrikki \& Wheatley, 2019) is trying to represent relevant aspects of all divergent approaches and find out which aspects are most meaningful. So, I don't actually have to pin myself down to one definition.

I should add, though, that in the work l've been doing l've been focusing on dialogue per se, and I fully appreciate that many definitions of dialogic pedagogy also address the broader classroom ethos, that is characteristics like open-mindedness, mutual respect, freedom from censure, reduced role division, space to explore and so on; Robin Alexander talked about this sort of thing in his keynote at this meeting. To make the research manageable, these characteristics have been considered just to the extent of being controlled for within our analyses rather than treated as central components. Nevertheless, I do think that by looking at a selected group of dialogue variables that has in some form or another been pinpointed from a wide range of different theoretical perspectives, we will eventually - maybe in another hundred years' time - achieve some collective understanding of what dialogic pedagogy is about. So that is where I am right now as regards definition.

\section{Eugene Matusov:}

Well, I don't want to be called "reactionary" [laughs], so I try to respond, not to react [to what was told before me]. Probably I want just to say what I like and dislike about different approaches to dialogic pedagogy. And let me start with what I dislike about other approaches to dialogue in education. I don't like instrumental dialogue in education. Instrumental dialogue is dialogue aimed to increase test scores, dialogue to increase argumentation, dialogue to increase critical thinking, you can put anything else in this list of educational outcomes. I think, essentially, dialogue, in my reading of Bakhtin, is non-productive, it can be by-productive, but it is non-productive. [In a genuine dialogue] we don't exactly know what we're doing, we don't know what we'll come up to, we don't know what task exactly we're trying to do... Even when we are doing any task, preset in advance - we may and will deviate from it in a genuine dialogue. Instrumental dialogue is a highly distorted and violent dialogue. This is what I don't like.

Let me switch to what I like. I like Bakhtin's idea that meaning-making is dialogic and that meaningmaking is a relationship between a question, asked by a person with an interest, urgency, curiosity and/or puzzlement, and an answer, which is provided in a serious way to that question by somebody else. Which means that education starts with the students' questions, not with the teacher's questions and that the asked questions are genuinely interesting for the students. And again, the questions might be not always well-defined or well-articulated. Dialogue might start with a student's tension or a vaguely articulated puzzlement or something like that. 
I like Bakhtin's notion of "consciousnesses with equal rights," when, again, basically, it's about the collapse of authority. First of all, it's about the collapse of institutional authority and teacher authority. I like the idea that dialogue cannot be forced. It's always voluntary. So school, conventional school, is antidialogical in this sense because it's often mandatory - society wants education for all students and defines what this education is about. And I like dialogue, in which the primary focus is not on the agreement and the consensus but on the misunderstanding, non-understanding, disagreements, puzzlement, and so forth. And I think I should finish maybe before my 2.5 minutes are over to give the floor to somebody else, thank you.

Provocation nr 2. Dialogue is too complex to be genuinely understood and captured by quantitative statistical methods. Quantitative studies of dialogue and argumentation impress at first sight because of their numbers, tables and figures and the enormous amount of work that has been put into developing coding schemes, training coders, achieving reliability and analyzing hundreds of turns and features. But I have yet to meet a quantitative study that gave me real insight into the workings of learning through dialogue and/or argumentation.

\section{Adam Lefstein:}

Generally, I'm sympathetic to the idea that systematic coding and statistical analysis do not often generate much insight into the dynamics of dialogue. For real insight, I much prefer the sort of careful, detailed, ethnographically informed case studies that stretch our educational imagination. For example, Ray McDermott's work on how a young girl hides her inability to read by bidding for a turn at the very moment when she won't be granted one, and how an entire class collude to help her achieve this goal (McDermott \& Tylbor, 1983). Or the analysis that led Ben Rampton to characterize whole class instruction as, and I quote, "a jostling but expressively depleted style of communication which marginalizes students' judgement but threatens to drag them onto the platform with curriculum-scripted performances that in the end don't actually count for very much" (Rampton, 2006).

I find that account to be far more helpful than the way many of us - myself included - describe traditional instruction with measures of closed questions, brief student responses and unelaborated teacher evaluation. Or, to provide an example that is closer to home, Cathy O'Connor and Sarah Michaels's careful analyses of the way teacher revoicing can reposition the student as having epistemic authority and thereby shape the ensuing interaction (O'Connor \& Michaels, 1993).

Likewise, I always found the case studies in Marty Nystrand and colleagues' Opening Dialogue, the ones that come after the statistical analyses and indeed problematize them, far more insightful than the statistical chapters (Nystrand, Gamoran, Kachur, \& Prendergast, 1997). BUT, that said, I probably wouldn't have read those case studies without the quantitative analyses, and likewise think that quantitative work in our field is absolutely crucial, because ethnographic insight is not the only game in town, or indeed not the most important one. So I'm wholeheartedly in favor of developing coding schemes, training coders, coding, analyzing etc. (especially if someone else is responsible), because without this we wouldn't be able to say much about populations, general trends, or cause and effect. So, for example, if we want to say something about the effects of dialogic teaching on students' learning, development or well-being, we're going to need to quantify variables. I doubt I need to say more about this here. 
So, let me just conclude with a thought about the danger of posing the discussion in terms of a paradigm war between qual and quant camps. When ethnographers dismiss quantitative studies as lacking in insight, and experimental psychologists respond by arguing that qualitative studies are not real science, the whole field suffers. So I hope we don't get too caught up on this question, at least in the way l've ended up framing my response to it here.

\section{Christine Howe:}

Dialogue is just one of numerous human social practices - and like all others, it is complex. Moreover, whenever quantitative methods are used to address such practices, they demand massive simplification. Nevertheless, it's my belief that fear of simplification has actually impeded progress in our field, because it has contributed to the under-researching of questions that can only be addressed through a quantitative approach. Some of these questions are pretty fundamental and ought to be addressed, including for instance whether any of this stuff actually makes a difference to how students perform. I do not think you can get a proper answer to that question using in-depth, qualitative methods. I don't want to belittle qualitative analyses. I agree with everything that Adam said about them. They play an indispensable role, but I do think that, if anything, the balance in this field has been towards the qualitative and not towards the quantitative and I think that has inhibited progress.

But coming back to what I said a moment ago, quantification absolutely demands simplification and some researchers are wary. The main thing l'd say to those researchers is that simplification is only a problem (and something to be fearful of) if it also results in meaninglessness - and you can do various things to check this out. For instance, in the study I have been presenting at this meeting (Howe et al., 2019) we sent transcripts of the classroom interactions we recorded to outside experts. These transcripts were chosen because they fell on a continuum of 'dialogicality' in terms of our quantitative analyses (and the crude and simple indices these required). Our experts included people for whom quantification is almost taboo. All experts were asked to rank-order the transcripts from most to least educationally productive, using their own perspective on (and criteria for) educational productiveness. Our quantitative indices strongly predicted the rankings, implying that they were meaningful proxies for something that was in fact much more subtle. In short then, there are ways in which you can cut across the barriers that exist in this field.

This said, our study focused on teacher-student dialogue and I don't see the study (or any other piece of work at present) as unambiguously addressing the processes by which teacher-student dialogue has its effects. However, this is a comment on the current state of the art, not a claim about a limitation-inprinciple on quantification, for studies of group work amongst students show that it is perfectly possible to address the 'workings of learning' through quantitative analysis. I could give many examples (including from my own work; Howe \& Zachariou, 2019) where, through quantitative comparison of experimental manipulations, the processes of growth (and specifically the role of dialogue in those processes) have been clarified. In the future, the same should be true of teacher-student dialogue.

\section{Eugene Matusov:}

I'll probably continue this discussion with "No, but". Do we have Norwegians here? No? because I wanted to refer to a very interesting fairytale. It's about a little goat, a kid, who learned how to count to ten (Prøysen, 1961). In the Norwegian fairytale, various animals got upset and angry with the little goat who was counting them until the little goat saved the animals from drowning by counting them on an overloaded boat. I think this story reflects that in some cultures, people find that counting people is disrespectful. Because it erases differences among people. It's like a headcount. Headcount is good for counting cows, 
but not always people. [For example, it is disrespectful to say that my mother has two children because she has my older brother Alex and me. We are not interchangeable "children" - we are unique Alex and Eugene for my mother and both of us.] So, in this sense, any quantitative research is anti-dialogic in its nature. And in this case, I will say: "No, quantitative research cannot be used for studying dialogue and dialogic pedagogy."

Now, I need to turn around and say "but". But - not everything is dialogue. We, humans, are not always engaged in dialogue and not all part of education, even a dialogic part, is completely dialogic. For example, sorry to say that but I have caught a cold here, in Israel, and I have to do like this (wiping his nose) and that's part of not being dialogic and not really even nice, but that's part of my body. And that part of this can be countable and you can count that. This counting is good, useful, and respectful. So, if you want to count not-dialogic aspects, - be my guest. But anything that is dialogic is not worth, legitimate, or respectful of counting because the dialogic focuses on uniqueness, on meaning-making, which is not countable. Because, again, counting is about erasing differences [but] meaning is about uniqueness (Matusov, Marjanovic-Shane, Gradovski, 2019; Matusov \& Marjanovic-Shane, 2018). That's my reply to that.

And actually, I agree with Antonia [Prof. Antonia Larrain, in the audience] for something that Bakhtin argued at the end of his life, which is developing "dialogic science." It is nothing like quantitative or qualitative. It is actually neither of them. Dialogic science has something to do with meaning-making. I'm sitting here replying and addressing people about their dialogic research. This is nothing to do with coding, like often in qualitative research, - it is something else. And we can talk more about that.

\section{Alina Reznitskaya:}

I agree that the quality of evidence we currently have to support our understanding of whether and how dialogue works is not very high. However, I think the problem is not with the use of quantitative methods, as the choice of methodology depends on the research question we want to address, and some research questions align better with quantitative approaches.

At the same time, I understand this critique of quantitative studies, and to me the most pressing problem is not having good models that clearly and convincingly specify what it means to 'make progress' in the context of dialogue and argumentation. For example, most existing quantitative measures of argumentation quality rely on structural analysis. That is, researchers (including myself) simply count the number of desirable argument elements (such as positions, supporting reasons, and opposing reasons) or language structures (such as phrases "I think... because"). This approach focuses on the form, and largely ignores the content of the arguments. And, although structural analysis can capture some aspects of quality argumentation, it often omits more important features of good arguments, such as accuracy, coherence, and persuasiveness.

On a positive note, there are many interesting proposals about improving measures of argumentation making them more nuanced and comprehensive. There is also interesting work being done in automated scoring that can make the analysis of arguments more efficient. In fact, I believe our current understanding about the educational potential of dialogue and argumentation will be considerably revised, once we make advances in the quality of our measurement tools. So, I would not give up on quantitative methodology, but instead suggest that we work to address existing challenges. 
Provocation nr. 3. Issues of social class, (in)equity, and accessibility to linguistic resources have been neglected in this research field. Enculturation into a particular, monolithic type of "ideal" academic discourse that is mainly based on rational reasoning and argumentation (typical of high SES families of particular cultures) disregards and disrespects the different registers of discourse minoritized students come to class with and alienates them from participation in classroom dialogue. To what extent does our work challenge or reify the implicit and explicit ways that schools fit minoritized students into singular or monolithic forms of thinking and discourse?

\section{Christine Howe:}

Well, I'm of a sufficiently advanced age to disagree with the first sentence in this provocation. This is because I remember that in the 1950's and 1960's there was in fact a lot of work into social class differences in classroom dialogue, associated in the UK primarily with the work of Basil Bernstein (see Williams, 1970). Bernstein drew attention to the 'restricted code' of dialogue that he regarded as characteristic of working-class interactions and the 'elaborated code' of dialogue that he saw as more typical of the middle class. He believed that working-class kids were disadvantaged in school (and middle-class kids advantaged) because the language of classrooms also relies on the elaborated code. The idea of elaborated dialogue is of course not a million miles away from some variables that are featuring (and being promoted) in contemporary work.

Now I also remember that the work of Bernstein and others at that time was strongly criticized for being demeaning of working-class culture, which the critics argued was just as rich linguistically as middleclass culture. At the time, I found their arguments compelling, so with that as a background, I actually feel quite nervous about engaging with this provocation. However, one possibly relevant thing I can say with reference to the study l've been talking about already (Howe et al., 2019), is that it was a naturalistic piece of work conducted in 72 classrooms that couldn't be more diverse in terms of socio-economic indicators within the English context $(0-100 \%$ of students in each classroom eligible for free school meals; 0-96\% from minority ethnic backgrounds). Yet we found absolutely no relationship between any demographic indicator and the use of the dialogue forms that we, and I think most people at this meeting, would regard as productive.

So, while the 72 classrooms actually varied greatly over their use of these dialogic forms, i.e. over how they managed to fit students into those forms, the variation is unlikely to be anything to do with students' social background - and what may or may not be true of their interactions at home. In other words, based on this recent study I would say that there is absolutely no evidence that certain forms of classroom dialogue are more accessible to middle-class children than to children from a highly deprived culture. And if these forms are as productive as we think they are, l'd be a little bit unhappy about holding them back from some groups rather than making them available universally.

\section{Alina Reznitskaya:}

I have no reservations about promoting the discourse of reasoned argumentation through my work in public classrooms. Moreover, I would argue that exposure to such discourse is especially valuable for minority groups who, on the one hand, may lack access to these ways of talking in their home environments, and, on the other hand, can and should benefit from acquiring this extremely useful cultural resource. 
Of course, this does not mean that other forms of expression should be excluded or disrespected. It also does not mean that teachers should ignore the differences between school and home cultures of minority students. In fact, teachers need to find ways to capitalize on those differences in order to broaden the repertoire of discourses available to all students.

\section{Adam Lefstein:}

I think our field needs to attend much more to the interaction of social class, culture, language and classroom dialogue. We know that student socioeconomic status shapes how dialogic pedagogy is enacted in the classroom. For example, Julia Snell and I worked with a group of teachers in London who believed that their low SES pupils suffered from linguistic deprivation that prevented them from participating effectively in dialogic teaching and learning. We know this because when we encouraged them to engage their classes in more challenging dialogue, they explained that their pupils come from working class families and suffer from linguistic and cultural deficits that make our suggestion impractical. These beliefs also influenced the way some of them managed dialogic teaching in their classrooms. They tossed softball questions to perceived "low ability" students, who in turn dodged those questions, thereby positioning themselves as incompetent, which reinforced their classroom identities as low ability and incapable of participating in dialogue (Snell \& Lefstein, 2018).

One aspect of this is the extent to which classroom dialogue privileges certain linguistic and cultural repertoires. I'm reminded, for example, of an episode in which one East London pupil read out the opening of his story to the class, while the teacher scribed his work on the overhead projector. "When we was in Year 4", the pupil read, and was immediately corrected by the teacher, "When we were ...". The pupil in turn corrected his teacher - he had written "we was", in accordance with the local, non-standard dialect. Teacher policing of pupil language threatens to shut down the discussion, alienate pupils and prevent them from expressing themselves in their own voices (Snell, 2013). Similarly, cultural and gender norms for negotiating disagreement vary, and we need to be respectful and accommodating of our students' different ways of engaging in discussion and argument, in order that all feel comfortable to express themselves.

That said, there was an implication in the provocation that rational reasoning itself has a class and cultural bias. This is a troubling assertion. Some forms of debate - for example, the highly explicit and formal argumentation you might find in a court room or an academic conference - are more customary in some homes - for example in homes of lawyers and academics. But that does not mean that reasoning is the exclusive domain of the upper classes. It means that we need to use multiple genres of discussion to give students access to multiple forms of discourse and interaction.

Nevertheless, every educational action is going to benefit some students more than others, and we need to study who are the winners and losers of different forms of dialogic pedagogy.

\section{Eugene Matusov:}

From my work on dialogic pedagogy, on the one hand, diversity is welcomed because, in a way, we're hunting for the difference, for the otherness. And this otherness ... could be in different socioeconomic classes, different religions, different political beliefs: different, different, different! Especially, minority! That's even better! Minority opinion, minority students, minority experiences, they are terrific for dialogue because they are close to the uniqueness (uniqueness is minority in its extreme) (Matusov, Marjanovic-Shane, Kullenberg, \& Curtis, 2019). So, I would say, on the one hand, we don't have much problem with this issue in dialogic pedagogy. 
On the other hand, we do have a problem with diversity in dialogic pedagogy. Because of many different things, like my ontological idea, my ontological dialogic pedagogy, is different from others, right? Which immediately means that there are particular values in our diverse versions of dialogic pedagogy. These different cultural values in our different versions of dialogic pedagogy promote particular cultures, particular interactional styles, and so forth.

So, the question is... On the one hand, I see the purpose of ontological dialogical pedagogy to be deconstructive: it is deconstructive of values, of everything. On the other hand, this deconstruction itself is a cultural value and some people might not accept this cultural value of pedagogy as deconstruction. I think there is an inherent tension there.

Dialogue is very verbal, right? But not every culture is verbal. I'm sorry, l'd disagree with what some people might say, but some cultures promote non-critical attitudes, and so forth. So, the question is that dialogic pedagogy contradicts many cultures and many ways of being, and many ways of acting in the world. And this is an interesting issue of how to deal with that.

And from that point of view, I don't want my dialogic pedagogy to monopolize education. It's one of many [pedagogies], I believe this is the best, but I also believe in educational pluralism. It's like paraphrasing the famous statement on freedom of speech, "l'd disagree with your pedagogy, but you should have the right to practice whatever pedagogy you think is good". So this is dialogical pluralism in education. Education should include all pedagogies: different educators who want to do education differently and for different purposes (Matusov \& Marjanovic-Shane, 2016).

[break for dyadic discussion, during which Eugene talked with Dr. Sherice Clarke in the audience]

Let me start with... Actually, this is my reply to Sherice. She told me that she disagrees with my position about what dialogic pedagogy is because she thinks that basically [I meant that], and I simplify, it's for the rich kids or for "the talented tenth", or something like that. And my reply to that is that I both agree and disagree with that.

So, let me start politely with why I agree. If you now look up the word "school", it is a Greek word that actually means leisure. And, of course, Ancient Greece, where the term emerged, was a slavery-based democratic state. You need to have slavery to have a school as a leisure, that's absolutely true. And in this sense, the dialogic pedagogy that I am talking about is for "the rich". But for any kind of institution, a society has to develop itself at a certain level to afford this institution, and for this kind of [institutional] affordances you have to be rich [enough].

And another reply to Sherice's critique is this: An American science fiction writer, William Gibson, said: "The future is already here - it's just not evenly distributed". We live in a society in which education is mostly instrumental because the whole business of education is to prepare humans to become like smart machines who can work predictably and reliably for the necessities-based society. My ontological dialogic pedagogy is a small, poorly protected, oasis of the future for lucky ones. Hopefully, maybe in the future, this need for instrumentality will disappear. Maybe faster than we think. Maybe a jobless society is coming to us now and it will create new possibilities for education. That's why I agree with you, Sherice, that my vision of dialogic pedagogy is for "the rich".

Why I disagree with you is because I think that ontological dialogic education is a part of the human rights, it's an existential human need of each person. I work actually with minority students, working-class students in the US, and in my view, (those) children and adults are extremely hungry for that type of 
education. Yes, it is not necessities-based education and, yes, often one has to fight for the necessities, that's true as well, that's a fact of our life.

Provocation nr. 4: In spite of extensive evidence about the benefits of dialogic pedagogy in classrooms, the impact of teacher professional development efforts to change classroom practices in this direction has overall been negligent. Why is it so hard? What, according to you, are the main obstacles or reasons for this failure?

\section{Eugene Matusov:}

I think it is very important how we, educational researchers, treat and address our colleagues, educational practitioners, how we say "they" - means "teachers." For me, this is not very dialogic - this is instrumental. Basically, we often try to impose our educational ideas, gained in our research, on teachers - to teach them how to do that. Teachers become instruments for us to implement our educational research findings and research-based visions. In my view, dialogue starts with "you" and not "they." At the same time, teachers often treat their students as "they" and this, probably, is why their pedagogy is not dialogic. There is a vicious, monologic, cycle of treating people as instruments or objects. This is, of course, from my view of dialogic pedagogy.

A part of what we are discussing here is what "good education" is - this is a good question. But I think this question is a part of education itself. I think it is a part of education itself to investigate with students (and their teachers) what good education is for them: to reveal alternative ideas about education and the values behind them and test these ideas about education against each other through and in education. In this endeavor, in this inquiry, we all are "you": students, teachers, and educational researchers. It is a dialogue. We are genuinely interested in each other and we are addressing and replying to each other.

However, this question about good education is a question primarily by and for the students because it is their education at the end of the day, not teachers or educational researchers. Second, it is the question of the teachers because the teachers facilitate students' search for and investigation of good education. Finally, it is the question of educational researchers because they help students and teachers.

Unfortunately, now it is the primarily question of researchers, or, maybe, of the state. And, it should definitely not the primary question of the state. I think the state should be kept out of this question entirely, limiting its role to securing resources for education.

Education is primarily the personal business of the students. Yes, students may need help with that: instructional, organizational, or financial, but this all is secondary. I see the role of educational researchers in listening to and recording diverse voices about this question of good education, bringing these diverse voices in dialogue, exploring them, provoking more dialogues and bringing them back to the students and the teachers for their deconstructive dialogues. Students author their own education, and their teachers help the students in authoring their own education. That is why the teacher's pedagogy is also authorial. Research is also authorial, rather than purely objective. And this is how dialogue happens, in my view: treating other people as authors in a dialogue. It is quite different from the current situation, when we, educational researchers, have already decided what is good through our research in advance, and the teachers must implement this goodness. This seems to me to contradict our value that good education must be dialogic. 


\section{Alina Reznitskaya:}

I would like to start by reacting to the first part of this statement, and to suggest that the quality (vs. quantity) of evidence we currently have to support the benefits of dialogic pedagogy in classrooms is not very high. The story of unmitigated success that we often hear and read about can be challenged by considering serious methodological problems present in many studies, measurement issues that I just talked about, as well inconsistent results, small effects sizes, and even publication bias; all problems that should be given much more attention.

Now, switching to the second part of the statement about the difficulties to change interactional patterns in the classroom. While we do have studies and programs that produced meaningful changes in classroom discourse (including our own work), the costs of achieving such results are high, as more effective programs require intensive and prolonged work with teachers.

In fact, Harvard researchers O'Connor and Snow, have compared some PD programs to demanding fitness routines "that only those with the most leisure time or other sources of support can keep up with" (O'Connor \& Snow, 1998). Other scholars also argued that our current PD programs are unnecessarily complex, and we may be better off by focusing instead on identifying and sharing with teachers a few 'high leverage' practices that can be readily learned by teachers and reproduced at scale.

That's an interesting point that can be investigated in future studies. I, however, have a different perspective. I think that both pre-service and in-service education has to be intellectually demanding, because what we asking teachers to do in the classroom is in fact complex and challenging, and it does require a lot of training (and re-training) to transition to the type of classroom discourse that truly supports more ambitious goals of education. If my position is correct (and, again, we would need to test all these assumptions), it would signal the need for a major revision of teacher preparation, with argumentation and discourse studies taking a more central role in pre-service and in-service education.

\section{Adam Lefstein:}

Why is changing practice so difficult? I want to touch here on four reasons. First, teaching practice is in and of itself difficult and complex work (see for example, Labaree, 2000). Teachers need to negotiate conflicting goals and agendas, both their own and those of their students. They need to manage multiple voices and bodies. This creates enormous complexity and uncertainty, which they must cope with at a brisk pace. Keeping all this together - for some $20 \mathrm{hrs}$ a week - is extremely difficult, even in so-called traditional instruction. Dialogic teaching amplifies the uncertainty and complexity, in part because it gives greater weight to student agency and ideas, and requires greater teacher flexibility and knowledge. At the same time dialogic teaching robs teachers of many of their existing tools to cope with teaching's difficulties. So, dialogic teaching is difficult, and educational systems are not well-designed to help teachers cope with these difficulties.

Second, classroom teaching and learning is a complex, interdependent system that comprises talk, topic, activity, assessment, physical organization, pupils, time, goals, curriculum, instructional tools, teacher beliefs and more. Each component influences the others. Talk is shaped by activity, by epistemological stances, by content, by assessment, and more. So, if we want to change talk, we have to attend to all the other aspects of the system, many of which are institutionally entrenched. For an example of institutionally entrenched forces, consider how pressures to succeed on standardized examinations incentivize students and teachers to not to "waste" time on dialogue. Now, given this claim that teaching and learning is a complex, interdependent system, I would question the premise of the question that teacher professional 
development - at least in the ways it's normally understood - could be sufficient to promote dialogue at scale. Teacher professional development is only one change lever, and not a particularly effective one at that. We need a more systemic approach.

Third, system capacity The move from changing practice in a handful of schools to changing practice across dozens or even hundreds of schools cannot be taken for granted. It requires infrastructure and expertise that are typically lacking in educational systems, and I should add in academic research groups. We in the dialogic education community have barely begun to think about how our systems work, let alone how to change them to support dialogic practice on a wide scale.

Finally, our own models of dialogic pedagogy. If our models are not gaining traction, perhaps we need to do some soul-searching about the models themselves. If they're not well-suited for existing conditions or create intolerable levels of uncertainty and complexity for teachers, then we also need to think about how to adapt our thinking about dialogic pedagogy to the reality to which we would like them applied.

\section{Christine Howe:}

Well, it's great to come fourth because many of the points I was going to raise have been raised already. I agree with Alina that the evidence isn't anything like as extensive as maybe our provocation suggests, and I agree with all the factors that Adam has identified. The difficulties teachers experience in mastering the practices and the lack of support from the wider contacts and so on are all extremely important. But that gives me enough space to be a little bit more provocative and to suggest that one other factor may be that the message we as researchers give to teachers isn't always as clear as it might be. It may even be muddled in certain respects.

To begin with, if we go back to the first of our provocations, which drew attention to a whole range of different ideas about dialogic pedagogy and learning, maybe teachers are hearing a mixture of ideas coming from different theoretical traditions and this is confusing (relevant studies are summarized in Howe \& Abedin, 2013). I certainly know of work that reports teachers talking about their difficulties with piecing together the messages they get from researchers who adopt a scaffolding perspective and the messages they get from researchers who come from a more interactive, egalitarian tradition. Even worse, to the extent that the different ideas about dialogic pedagogy and learning are contradictory (and some may be), they can't all be correct, so perhaps some teachers have negative experiences when they try to implement, in other words experience no positive impact on students. In addition, I think that quite often we try to do too much, too quickly. Dialogic pedagogy, no matter what form it takes, comprises a very wide range of different components, and it's tempting to address them all simultaneously. Maybe this is asking teachers to do too much. We might be more successful if we took a few steps at a time, bringing a small number of 'certs' into classroom practice and gradually building on them. The outcome might not initially be optimal but at least there should be some durable, positive consequences.

\section{References}

Gregory, M. (2007). Normative dialogue types in philosophy for children. Gifted Education International, 22, 160-171.

Howe, C., \& Abedin, M. (2013). Classroom dialogue: A systematic review across four decades of research. Cambridge Journal of Education, 43, 325-356. 
Howe, C., Hennessy, S., Mercer, N., Vrikki, M., \& Wheatley, L. (2019). Teacher-student dialogue during classroom teaching: Does it really impact upon student outcomes? Journal of the Learning Sciences, 1-51.

Howe, C., \& Zachariou, A. (2019). Small-group collaboration and individual knowledge acquisition: The processes of growth during adolescence and early adulthood. Learning and Instruction, 60, 263274.

Labaree, D. F. (2000). On the nature of teaching and teacher education - Difficult practices that look easy. Journal of Teacher Education, 51(3), 228-233.

Lefstein, A. (2010). More helpful as problem than solution: Some implications of situating dialogue in classrooms. In K. Littleton \& C. Howe (Eds.), Educational dialogues: understanding and promoting productive interaction (pp. 170-191). Abingdon, Oxon: Routledge.

Lefstein, A., \& Snell, J. (2014). Better than best practice: Developing teaching and learning through dialogue. Abingdon, Oxon: Routledge.

Matusov, E., \& Marjanovic-Shane, A. (2016). Radical Proposal for Educational Pluralism and The State's Educational Neutrality Policy. Dialogic Pedagogy: An International Online Journal, 4. doi:http://dx.doi.org/10.5195/dpj.2016.170

Matusov, E., \& Marjanovic-Shane, A. (2018). Teaching as dialogic conceptual art. Knowledge Cultures, 6(2), 9-27. doi:10.22381/KC6220182

Matusov, E., Marjanovic-Shane, A., Kullenberg, T., \& Curtis, K. (2019). Dialogic analysis vs. discourse analysis of dialogic pedagogy: Social science research in the era of positivism and post-truth. Dialogic Pedagogy: An International Online Journal, 7, E20-E62. doi:10.5195/dpj.2019.272

Matusov, E., Marjanovic-Shane, A., \& Gradovski, M. (2019). Dialogic pedagogy and polyphonic research art: Bakhtin by and for educators. Palgrave Macmillan.

McDermott, R. P., \& Tylbor, H. (1983). On the necessity of collusion in conversation. Text, 3(3), 277-297.

Nystrand, M., Gamoran, A., Kachur, R., \& Prendergast, C. (1997). Opening dialogue: understanding the dynamics of language and learning in the English classroom. New York: Teachers College Press.

O'Connor, C., \& Snow, C. E. (2018). Classroom discourse: What do we need to know for research and for practice? In M. Schober, A. Britt, \& D. Rapp (Eds.), The Routledge Handbook of Discourse Processes (2nd ed., pp. 315-342). New York: Routledge.

O'Connor, M. C., \& Michaels, S. (1993). Aligning academic task and participation status through revoicing: Analysis of a classroom discourse strategy. Anthropology \& Education Quarterly, 24(4), 318-335.

Prøysen, A. (1961). The goat that learned to count. St. Louis, MO: Webster

Rampton, B. (2006). Language in Late Modernity: Interaction in an Urban School. Cambridge: Cambridge University Press.

Snell, J. (2013). Dialect, interaction and class positioning at school: From deficit to difference to repertoire. Language and Education, 27(2), 110-128.

Snell, J., \& Lefstein, A. (2018). "Low ability," participation, and identity in dialogic pedagogy. American Educational Research Journal, 55(1), 40-78. 
Walton, D. (1998). The new dialectic: Conversational contexts of argument. Toronto, CA: University of Toronto Press.

Williams (Ed.). (1970). Language and poverty: Perspectives on a theme. Chicago: Markham Publishing Company.

\section{(cc) EY}

New articles in this journal are licensed under a Creative Commons Attribution 4.0 United States License.

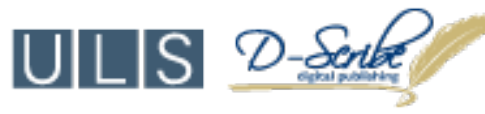

This journal is published by the University Library System, University of Pittsburgh as part of its D-Scribe Digital Publishing Program and is cosponsored by the University of Pittsburgh Press. 